\title{
El efecto financiero y social que causa la compensación universal al fisco mexicano como medio de extinción de una obligación
}

\section{The financial and social effect that causes the universal compensation to the mexican fisk as a medium of extincion of an obligation}

\author{
PUENTES-MEDINA, Horacio $\dagger^{*}$, ROCHA-LÓPEZ, Marcela y SILVA-ROBLES, Jorge \\ Universidad Tecnológica del Norte de Aguascalientes. Carretera Valle de Santiago - Huamimaro Km. 1.2, 20 de \\ Noviembre, 38400 Valle de Santiago, Gto.
}

ID $1^{\text {er }}$ Autor: Horacio, Puentes-Medina / ORC ID: 0000-0002-8080-4337

ID $1^{\text {er }}$ Coautor: Marcela, Rocha-López / ORC ID: 0000-0002-1880-7633

ID 2do Coautor: Jorge, Silva-Robles / ORC ID: 0000-0002-0289-4461

DOI: $10.35429 / J L A .2019 .9 .3 .23 .36$

Recibido 01 de Mayo, 2019; Aceptado 30 de Septiembre, 2019

\begin{abstract}
Resumen
La afectación financiera y económica a los contribuyentes con la entrada en vigor de la reforma al artículo 25 fracción VI inciso a) de la Ley de Ingresos de la Federación en 2019, por medio de la cual se elimina a la compensación universal de los impuestos, tiene muy desalentados a los causantes, ha repercutido en el crecimiento del 0.002 (el cero punto, cero, cero dos por ciento) del producto interno bruto de economía en el año del 2019, la cual se vio afectada por el incremento de: $\$ 130,500,000,000.00$ ciento treinta mil quinientos millones de pesos en los últimos tres años, por la aplicación de la extensión de las obligaciones y que representó el $48.4 \%$, en comparación con el dos mil catorce, han puesto a temblar a la administración encabezada por Andrés Manuel López Obrador, a la Secretaría de Hacienda y Crédito Público y al Banco de México, esto sin dimensionar que algunas empresas tomarían el camino del hartazgo y optarían por buscar el amparo y la protección de la justicia federal, como el caso de la compañía Rex Irrigación Zacatecas, S.A. de C.V.
\end{abstract}

Afectación, Incremento, Amparo

\begin{abstract}
The financial and economic impact on taxpayers with the entry into force of the amendment to article 25 section VI subsection a) of the Federation's Income Law in 2019, by means of which the universal compensation of taxes is eliminated, It has discouraged the causes, it has had an impact on the growth of 0.002 (zero point, zero, zero two percent) of the gross domestic product of the economy in the year of 2019, which was affected by the increase of: $\$$ $130,500,000,000.00$ percent thirty thousand five hundred million pesos in the last three years, due to the application of the extension of obligations and which represented $48.4 \%$, compared to two thousand fourteen, have shaken the administration headed by Andrés Manuel López Obrador, to the Ministry of Finance and Public Credit and to the Bank of Mexico, this without dimensioning that some companies would take the path of fatigue and opt for $b$ use the protection of federal justice, as in the case of the company Rex Irrigation Zacatecas, S.A. from C.V.
\end{abstract}

Affectation, increase, protection

Citación: PUENTES-MEDINA, Horacio, ROCHA-LÓPEZ, Marcela y SILVA-ROBLES, Jorge. El efecto financiero y social que causa la compensación universal al fisco mexicano como medio de extinción de una obligación. Revista de Aplicaciones del Derecho. 2019. 3-9: 23-36.

\footnotetext{
*Correspondencia al Autor (Correo Electrónico: medina@hotmail.com)

$\dagger$ Investigador contribuyendo como primer autor.
} 


\section{Introducción}

En la actualidad los contribuyentes se ven muy afectados financiera y monetariamente en el cumplimiento de sus obligaciones con el fisco federal mexicano, esto se da por el diminuto crecimiento de la economía nacional en el ejercicio fiscal del dos mil diecinueve y que con toda oportunidad fue señalado por el periódico el Financiero, el cual será aproximadamente del 0.002 "cero punto, cero, cero dos por ciento" del producto interno bruto según le informó a ese medio de comunicación el banco Citibanamex, es decir, será casi nulo el incremento de la riqueza del país que fue estimada por el gobierno federal y por consecuencia no se verá reflejado en el bolsillo de los mexicanos bajo ninguna circunstancia (El Financiero, 2019). De acuerdo con las políticas de austeridad instauradas por la Secretaría de Hacienda y Crédito Público y el gobierno federal (Secretaría de Hacienda y Crédito Público, 2017), han sido una desilusión total para los causantes, ya que al disminuir el estado el gasto público generó desconfianza en algunos capitalistas y el retiro de sus inversiones, lo que ha provocado desempleo, falta de consumo mayorista por el desacierto en la colocación del flujo monetario, la mayoría de las empresas buscan otras medidas de eliminar o extinguir sus obligaciones fiscales; ya que la generalidad de ellas no cuentan con liquidez y buscan solventar el pago de sus impuestos sin desembolsarlos de sus cuentas bancarias, esto se da a través de la figura de la compensación universal que se deben enterar al Servicio de Administración Tributaria de manera mensual, semestral o anual según sea el régimen en el cual se encuentre tributando el causante. Los Senadores de la bancada del PAN y de MORENA señalaron que la Secretaría de Hacienda y Crédito Público les informó del incremento desmedido del cuarenta y ocho punto veinticuatro por ciento en los trámites de extinsión de obligaciones, lo que se inicio con un monto de $\$ 130,500,000,000.00$ ciento treinta mil quinientos millones de pesos dentro del rubro de las compensaciones universales durante el dos mil catorce, tuvo un incremento desmedido en tan sólo tres años por la cantidad de $\$ 134,000,000,000.00$ ciento treinta y cuatro mil millones de pesos, pasando en el dos mil diecisiete a la cuantía de $\$ 260,500,000,000.00$ doscientos sesenta mil quinientos millones de pesos (Saldivar, B, 2019).
El incremento en las compensaciones preocupó y alteró demasiado a la administración encabezada por Andrés Manuel López Obrador y a la Secretaría de Hacienda y Crédito Público y al Banco de México, lo que generó una desaceleración de la economía de acuerdo con el Servicio de Administración Tributaria y una evasión fiscal desmedida por la utilización incontrolable de los saldos a favor por las acciones ilícitas cometidas por algunos contribuyentes y que a la fecha les ha dado un resultado muy favorable en los bolsillos de los causantes.

Sabemos de antemano que son la mismas autoridades federales, estatales $y$ municipales las que han incitado al contribuyente a que caiga en situaciones adversas al solicitarles que emitan facturas por operaciones inexistentes, las cuales representan a la cantidad de un billón de pesos informó la Procuraduría Federal de Contribuyentes durante el foro de Corrupción de Empresas Fantasmas (ABCNOTICIAS, 2019), propuesta de reforma legal para su combate eficaz, en las cuales el estado mexicano participa con el setenta por ciento de desvíos e impunidad según la propia dependencia, y por consecuencia le resulten cantidades abismales de contribuciones a pagar a los contribuyentes involucrados, y es por eso que adoptan medidas ilegales para tratar de mermar el pago de los impuestos a través de la compensación universal, creándole un perjuicio enorme a los causantes cumplidos, y resultando absurdo el pretender eliminar el trámite de compensación cuando existe una corrupción enorme en el aparato burocrático del país. 


\section{Justificación}

Con esta investigación que se efectúa daremos cuenta a la sociedad de los daños y perjuicios que le ha causado la entrada en vigor del artículo 25 fracción VI inciso a) de la Ley de Ingresos de la Federación para el 2019, el cual publicado el día 28 de diciembre del 2018 en diario oficial de la federación que elimina a la compensación universal, este proemio viola al principio de legalidad tributaria contenida en el artículo 31 fracción IV de la Constitución Política de los Estados Unidos Mexicanos, y quebranta el artículo 23 del Código Fiscal de la Federación, al articulado $6^{\circ}$ de la Ley del Impuesto al Valor Agregado, y a los apartados 2185, 2186 y 2194 del Código Civil Federal, pues de manera ilegal el Servicio de Administración Tributaria no les permite a los causantes poder realizar el pago de sus obligaciones fiscales a través de la compensación y la extensión de las obligaciones.

La Secretaría de Hacienda y Crédito Público y el Ejecutivo Federal justifican su actuación en un incremento en la evasión fiscal por parte de los contribuyentes aplicando compensaciones al pago de los impuestos en la cantidad de $\$ 134,000,000,000.00$ ciento treinta y cuatro mil millones de pesos, pasando en el dos mil diecisiete a la cuantía de $\$ 260,500,000,000.00$ doscientos sesenta mil quinientos millones de pesos (ABCNOTICIAS, 2019)., sin imaginar el quebranto en el bolsillo de los contribuyentes cumplidos que todos los días luchan por mantener en pie a su empresa, quitándoles el beneficio de la compensación universal en materia fiscal en tiempos de recesión económica, de falta de liquidez monetaria, por la baja en las ventas y el aumento en el desempleo, y sobre todo de desconfianza de los capitalistas de invertir en territorio mexicano por el hecho de sentirse inseguros y amenazados por la políticas de austeridad implantadas por el gobierno federal al no haber crecimiento en el producto interno bruto de la nación.
La opción a la cancelación en irse directamente al amparo indirecto sobre el primer acto de aplicación de la compensación universal ante los tribunales competentes, esto con la esperanza de que les restablezcan a los contribuyentes el derecho a extinguir sus obligaciones fiscales a través de la aplicación de la ley sin tener que desembolsar de su cuenta bancaria el importe del pago de las contribuciones, y en ese sentido buscar formas legales de solventar sus deudas y deberes a favor del fisco mexicano.

\section{Problema}

El problema que afronta actualmente la sociedad mexicana es que la población ya no está dispuesta a pagar los $\$ 340,000,000,000.00$ trescientos cuarenta mil millones de pesos, o los $\$ 17,000,000,000.00$ millones de dólares que representa el cáncer de la corrupción e impunidad, la comunidad está cansada, azotada y muy devastada por tanto chantaje cometido por nuestros gobernantes de manera generalizada, así como por las acciones y los actos administrativos que realiza el estado mexicano a través funcionarios públicos que lo representan (Elizabeth, 2017).

Es sabido por todos y cada uno de los integrantes de la colectividad, que la corrupción se efectúa cotidianamente de manera incesante por los empleados de los distintos poderes, violando de manera irracional las normas jurídicas, buscando en todo momento la impunidad y la inaplicación de las leyes a los actos de descomposición que se realizaron por sus propios amigos $y$ colaboradores que administran, dirigen, contralan, revisan y juzgan a las actos que efectúan los burócratas, haciendo a un lado la aplicación del derecho, así como de los daños y perjuicios que le causan al estado mexicano, a su gente y a su patrimonio, ya que se dejan de aplicar programas de asistencia social e infraestructura en obra pública en detrimento de las clases más necesitadas y desprotegidas de este país.

Como podemos observar dentro de este documento el nivel de corrupción es muy alto y el de impunidad se encuentra en segundo lugar a nivel internacional, la pregunta sería ¿cómo se podrá disminuir en un 70 por ciento la corrupción, y en un 90 por ciento la impunidad en nuestro país? 


\section{Hipótesis}

Se reducirá exponencialmente en más de un setenta por ciento la facturación de las operaciones ilícitas e inexistentes con empresas fantasmas, para aumentar la recaudación fiscal en comparación con el año del dos mil diecisiete en más de $\$ 189,350,000,000.00$ ciento ochenta y nueve mil trescientos cincuenta millones de pesos, con la aplicación estricta de las normas penales y su debido proceso, con modificaciones adecuadas a las leyes secundarias, con una revisión física y material de las instalaciones, de sus procesos productivos y de sus empleados, utilizando la autoridad fiscalizadora la más avanzada tecnología satelital para descubrir y materializar la ubicación de las empresas que emiten comprobantes falsos por acciones aparentes, esto sin dañar las operaciones de terceros o contribuyentes que son cumplidos en sus obligaciones, y sobre todo que no se le restrinja el beneficio de la compensación universal en materia fiscal a la compañía Rex Irrigación Zacatecas, S.A. de C.V., sin la necesidad de irse ante los tribunales para su resolución, castigando con todo el peso de la ley a los servidores públicos deshonestos del gobierno federal, estatal y municipal que permiten la ejecución de esas acciones que tanto daño le causan al estado mexicano.

\section{Objetivos}

\section{Objetivo General}

Establecer nuevos elementos y normas flexibles por parte de la autoridad tributaria que le permitan reducir exponencialmente en más de un setenta por ciento la facturación de las operaciones ilícitas e inexistentes con empresas fantasmas, y que la contribuyente Rex Irrigación Zacatecas, S.A. de C.V., siga obteniendo el derecho a la compensación universal a través del amparo directo 618/2019 el cual fue presentado ante el Tercer Juzgado de Distrito con sede en la ciudad de Zacatecas Capital, con el objeto de eliminar en lo futuro el buscar litigios que sólo ocasionan desequilibrio económico y financiero a todos los contribuyentes cumplidos.

\section{Objetivos específicos}

- Se reducirá exponencialmente en más de un setenta por ciento la facturación de las operaciones ilícitas e inexistentes de empresas fantasmas utilizando el SAT la tecnología más avanzada para descubrir la ubicación de las empresas y sus operadores.

- Aumentar la recaudación fiscal en comparación con el año del dos mil diecisiete en más de $\$ 189,350,000,000.00$ ciento ochenta y nueve mil trescientos cincuenta millones de pesos, con la aplicación estricta de las normas penales y su debido proceso como se ha explicado dentro de este instrumento.

- Reducir el importe de $\$ 260,500,000,000.00$ doscientos sesenta mil quinientos millones de pesos, por operaciones inexistentes durante los primeros dieciocho meses, hasta alcanzar sólo el importe de $\$ 81,150,000,000.00$ ochenta y un mil ciento cincuenta millones de pesos, castigando con todo el peso de la ley a los burócratas deshonestos del gobierno.

- Recuperar la credibilidad de los gobernados a corto plazo, sobre el trabajo y los actos administrativos que realizan las instituciones gubernamentales en todos y cada uno de sus niveles.

- Rescatar el apartado de la extinción de las obligaciones señaladas en los proemios 2185, 2186 y 2194 del Código Civil Federal con el objeto de los contribuyentes incrementen su producción, consumo y distribución de sus bienes y servicios generando riqueza al país y su crecimiento económico.

\section{Marco Teórico}

La extinción de las obligaciones nace desde el momento mismo de la creación del hombre y empieza aproximadamente hace 10,000 años a.C. desde el nacimiento de la agricultura cuando el ser humano empieza cultivar y a sembrar la tierra para sobre existir y generar productos para el comercio (Marino, 2019). 
Los fenicios en año 6000 a.C. en la antigua Mesopotamia fueron los iniciadores del trueque el cual consistía lo que una persona tenía y no necesitaba se cambiaba por la que el otro que la poseía, el intercambio de productos se daba con plumas, pieles, cereales, animales, vestidos, etc., con el objeto de realizar el pago o compensación para extinguir las obligaciones que se realizan entre los comerciantes, los babilonios llegaron a ser un fuerte líder a nivel cultural, religioso y político de su época. Su vigencia como imperio data desde el año 1792 a.C. hasta el 539 a.C., durante dicho período su territorio se expandió hasta llegar a ocupar las ciudades que pertenecían a culturas más antiguas del mundo arcaico por medio de la cual se deba la compensación del pago en especie de una cosa por otra (Marino, 2019).

Los historiadores señalaban que el comercio nace en el año 6000 a.C. , aparecen las primeras monedas acuñadas con carácter oficial en la edad antigua 3000 a.C., y finales siglo $\mathrm{V}$ d.C. las mercancías como medio de pago resultaban ser poco prácticas, ya que muchas de ellas eran perecederas y difíciles de acumular, sin embargo en la edad media y sobre el siglo V y siglo XV d.C. en este periodo empiezan a surgir importantes rutas comerciales transcontinentales que intentan suplir la alta demanda europea de bienes y mercancías y que servían de caminos para reactivar la economía de numerosas regiones del mundo (Bonilla, 2013).

La eliminación de las obligaciones en el derecho romano y en la época clásica se conocía como el cumplimiento de las obligaciones por medio del cual la prestación de dare se verificaba mediante su solutio o pago, es decir, mediante cualquier acto formal o real que consistiera en una datio y, por lo tanto, constituyera el dominio de un derecho real (Paulino, 2010).

El derecho romano contempla dentro de sus apartados a la compensación como un pacto de non petendo, es decir, un pacto no pedido de acuerdo con la doctrinaria Libia Reyes Mendoza en su texto Derecho Romano II, y señala que normalmente se extingue una obligación cuando le ha dado total cumplimiento el deudor, pero pueden operar con la ayuda de una excepción, ope exceptionis como lo es la compensación (Reyez, 2012).
La compensación es otra forma de extinción de la obligación, cuando dos personas son deudoras la una de la otra, es decir, el deudor opone al acreedor un crédito que tiene a su vez en contra de éste y se tenía que cumplir con lo siguiente: que las deudas estuvieran vencidas, que el acreedor y el deudor tuvieran el mismo objeto, que las deudas y las obligaciones fueran igualitarias entre sí, que fueran líquidas y válidas.

Por consiguiente amigos lectores, el concepto de obligación puede expresarse como el deber del deudor de pagarle al acreedor, y se le conoce como el vínculo jurídico entre dos partes: el acreedor (creditor) y el deudor (debitor), el acreedor está facultado a exigir al deudor comprometido a cumplir un determinado comportamiento positivo o negativo que denominamos prestación, y si éste no cumple con la obligación debida de pagarle al acreedor, se le somete al sufrimiento de un perjuicio para la recuperación de su bien (Fernández, 2017).

La regla en Roma era que los contratos se extinguían por los mismos medios que servían o sirvieron para crearlos, es decir, las obligaciones se extinguían por un modo análogo a aquel con que se formaron, y en ese sentido un modo de extinción de las obligaciones en Roma era a través de dos medios: unos de derecho civil y otros de derecho pretoriano, los cuales señalaban que toda obligación podía extinguirse por una convención en que las partes interesadas, siempre y cuando los participantes fueran capaces de disponer libremente de lo suyo, y dejaban sin efecto o daban por nulas las obligaciones, o lo solucionaban por medio del pago en efectivo, por la novación, por la transacción, por la remisión, por la compensación, por la confusión, por la pérdida de la cosa que se debe, por la declaración de nulidad o por la rescisión, por el evento de la condición resolutoria y por la prescripción (Gómez, 2014).

El concepto de compensación que proporciona el Diccionario Jurídico Mexicano de Carmen García Mendieta del año de 1994 de la Suprema Corte de Justicia de la Nación (Montoya, 2018), señala que, en México, el Código Civil para el Distrito Federal acoge el instituto de la compensación en el capítulo I del título V, extinción de las obligaciones. 
El artículo 2185 dice que "tiene lugar la compensación cuando dos personas reúnen la calidad de deudores y acreedores recíprocamente y por su propio derecho". Y el artículo 2186 expresa: "el objeto de la compensación es extinguir por ministerio de la ley las dos deudas, hasta la cantidad que importe la menor".

Los orígenes de la compensación de daños y reparación civil por parte del estado fue durante la normalización jurídica como parte de la independencia y su consolidación, así fue como se acomodaron diversos créditos contra el erario público, asumidos plenamente como deuda pública, muestra de ello citamos la orden del 25 de octubre de 1821, dada con el objeto de que una junta reúna las escrituras y comprobantes para la clasificación de la deuda del imperio, el reconocimiento y clasificación de todos los créditos, a fin de que se anticipe este trabajo y puedan los juzgados resolver cuáles deban reconocerse por el imperio y términos de su satisfacción.

Legislación Mexicana, colección completa de las disposiciones Legislativas expedidas desde la Independencia Dublán Manuel y José María Lozano, Tomo I Número 253. Así como el Decreto del 28 de junio de 1824 mediante el cual: "el soberano congreso general constituyente de los Estados Unidos Mexicanos queriendo dar su testimonio de su respecto a la fe pública y de su rigurosa observancia de los principios de justicia, para arreglar y afianzar sobre bases sólidas el crédito nacional, ha tenido a bien decretar lo siguiente: se reconocen las deudas contraídas en la nación mexicana por el gobierno de los virreyes, hasta 17 de Setiembre de 1810. También reconocieron con igual carácter derechos a compensaciones, pensiones o indemnizaciones, así como las pensiones reconocidas para viudas, padres y madres pobres de los soldados insurgentes con total arreglo a la primera orden del gobierno español de 1811 (García, 2014).

Los principales documentos de análisis a juicio de Álvaro Castro Estrada, serían demostrativos de responsabilidad directa del estado; normas expedidas ex profeso, autorizando pagos con clara intención de recompensar.
De este tipo fueron las leyes para resarcir a persona determinada por la pérdida de intereses que empleó en el servicio nacional en la expedición contra los españoles en Tampico y la indemnización a súbditos por las pérdidas que sufrieron provocadas en el accionar de las tropas del gobierno en la toma de Zacatecas el 11 de mayo de 1835, así como la indemnización concedida por el perjuicio que sufre un convento en el incendio de pólvora del 23 de abril de 1834, sobre el resarcimiento de pérdidas y premio que se concede al $\mathrm{C}$. Federico Doring de acuerdo con la ley del 10 de noviembre de 1836, que le autoriza al gobierno a indemnizar a los súbditos por los hechos del 11 de mayo de 1835. Decreto del 2 de mayo de 1849 sobre la indemnización concedida a la Cruz de Querétaro.

Como hechos oficiales causantes de reparación por parte del gobierno y por razones no militares figuraron en 1853 , hechos que originaban pagos a cargo del erario con fundamento en el decreto del gobierno, número 3862 de 25 de mayo de 1853 a través del Reglamento de la Ley para el arreglo del contencioso administrativo de igual fecha Número 3861.

$\mathrm{Si}$ tales normas se hubiesen dictado durante la vigencia de la Constitución de 1857 o de la Constitución de 1917, por ser leyes especiales seguramente podrían haber sido impugnadas conforme a lo dispuesto primero en los artículos 12 y 13 citados de la Constitución federal. El instituto de la compensación económica en el Código Civil y Comercial es de vasta aplicación en el mundo moderno, tanto en sus aspectos civiles como mercantiles, y aun internacionales, el instituto toma su fuente de la llamada prestación compensatoria, la cual tiene un origen relativamente reciente.

Aparece en Europa en el último cuarto del siglo XX acusando diversidad de fundamentos y escasas raíces doctrinarias anteriores. Las reformas legislativas familiares en Francia, Dinamarca, Gran Bretaña, Italia, España y Alemania la adoptan, aunque con distintas características, asignándole funciones específicas y acomodando su particular fisonomía jurídica a la idiosincrasia y condicionamientos sociales de cada país. 
La doctrina y jurisprudencia en general, destacan el fundamento de esta clase de prestación, en la intención de compensar a quien sufre una pérdida del nivel de vida que gozaba durante el matrimonio o la convivencia.

El Código Civil y Comercial de la Nación incorpora esta novedosa figura, que de alguna manera viene a reemplazar el tradicional instituto de los alimentos entre cónyuges. En el anterior sistema, los alimentos se otorgaban como beneficio a favor de quien no hubiera dado causa a la crisis matrimonial del cónyuge inocente.

De esta manera, se le aseguraba a través de un pago periódico, el mantenimiento del nivel de vida del que gozaba durante la convivencia de acuerdo al Código Civil.

La diferencia esencial entre la cuota alimentaria y la compensación consiste en que la primera tiene por objeto el sostenimiento del alimentado a través del tiempo, conforme a sus necesidades y a las posibilidades del alimentante, por lo cual la pensión alimentaria está sujeta a variación según los presupuestos de hecho que le dieron origen.

En cambio, la compensación económica busca atenuar el desequilibrio y empeoramiento en la situación patrimonial de uno de los cónyuges a causa del divorcio o la ruptura de la convivencia (Bedrossian, 2017).

La compensación universal está contemplada en el artículo 23 del Código Fiscal de la Federación a partir de julio de 2004, forma parte de nuestra historia reciente; recordemos que antes de esa fecha, la compensación de saldos a favor sólo se permitía contra adeudos derivados de la misma contribución, lo cual era incomprensible para el contribuyente.

La compensación es una figura prevista en el Código Civil que establece que tiene lugar cuando dos personas reúnen la calidad de deudores y acreedores recíprocamente y por su propio derecho, a efecto, de extinguir las dos deudas, hasta el importe de la menor (Boletin Fical: EY, 2019).
Como podemos observar la eliminación de la compensación universal según Ricardo Homs es inadmisible, él comenta que en un país donde el crédito bancario es carísimo y donde el gobierno federal cobra tasas muy elevadas de impuestos directos e indirectos, donde el eliminar la compensación universal es quitarle dinero fresco a los contribuyentes, y que de acuerdo con los diputados representan la cuantía de $\$ 500,000,000,000.00$ quinientos mil millones de pesos, por lo que con esta modificación les afectará de manera directa en el bolsillo y en la percepción de los contribuyentes sobre la realidad que vive en el estado mexicano (Homs, 2019).

De acuerdo con los criterios generales de política económica 2019, la tendencia de los montos de las compensaciones que los causantes han aplicado en los últimos años ha tenido un crecimiento injustificado, de ahí el argumento de evitar la evasión fiscal.

Entre 2014 y 2017 el monto de saldos a favor del impuesto al valor agregado utilizados para acreditar el pago de otros impuestos pasó de 131.4 a 260.5 mil millones de pesos, un crecimiento real de 76\% (Salomón, 2018).

La realidad es que con la entrada en vigor del artículo 25 fracción VI inciso a) de la Ley de Ingresos de la Federación para el 2019 y publicado el día 28 de diciembre del 2018 en el Diario Oficial de la Federación, el Servicio de Administración Tributaria dejó sin efectos la compensación universal de los impuestos señalada el articulo 23 primer párrafo del Código Fiscal de la Federación el principio de la extinción de las obligaciones en materia civil, por lo que no puede compensar en la página del SAT y declarar conforme a derecho la presentación de mis declaraciones, dejando de observar los apartados $1^{\circ}, 5^{\circ}, 14,16$ y 31 fracción IV de la Constitución Política de los Estados Unidos de México, así como del proemio 23 del Código Fiscal de la Federación y de los artículos $5^{\circ}$ fracción $\mathrm{V}$ inciso a) y $6^{\circ}$ de la Ley del Impuesto al Valor Agregado, así como de los apartados 2185, 2186 y 2194 del Código Civil Federal y haciéndolo inconstitucional dicho proemio. 
Cabe señalar al respecto, que el importe del saldo a favor del impuesto al valor agregado se genera y determinado por la propia operación natural de las negociaciones gravadas a la tasa del $0 \%$ por venta de sistemas de riego agrícola y la venta de productos agropecuarios, etc., que realiza cualquier compañía conforme a derecho, y que dicho remanente se determina con el objeto de extinguir mis obligaciones tributarias en términos del proemio 23 del Código Fiscal de la Federación, y el Servicio de Administración Tributaria de manera maligna le restringió el derecho a realizarlo a la compañía, ya que no habilitó la opción para realizar la compensación de acuerdo con la captura de pantalla donde se demuestra que se encuentra bloqueada e inhabilitada la opción de compensaciones por lo que la autoridad fiscalizadora de manera inadmisible violó en mi perjuicio de la compañía los artículos $1^{\circ}, 8^{\circ}, 14,16$ y 31 fracción IV de la Constitución Política de los Estados Unidos de México, así como los principios de seguridad jurídica y de garantía de audiencia, así como lo que indica el artículo 23 del Código Fiscal de la Federación y lo que señalan los artículos 2185, 2186 y 2194 del Código Civil Federal que hacen referencia única y exclusivamente al capítulo de la compensación y en particular a la extensión de las obligaciones, donde claramente se demuestra que una norma en particular deroga a un general, por lo que no existe ningún impedimento legal para restringirle el derecho a la compensación universal a mi representada en términos de ley.

\section{Metodología de Investigación}

Para poder llevar a cabo nuestra exploración y el desarrollo de nuestra hipótesis se realizará un cálculo aritmético y un estudio de fondo y de forma sobre la compensación universal entre los contribuyentes que realizan actividades comerciales a la tasa del cero por ciento y a los cuales el Servicio de Administración Tributaria no les reconoce el principio general la procedencia de la compensación universal en materia fiscal señalado en los artículos 23 primer párrafo del Código Fiscal de la Federación, y lo que marca el proemio $6^{\circ}$ de la Ley del Impuesto al Valor Agregado, así como lo indican los articulados 2185, 2186 y 2194 del Código Civil Federal, disminuyendo el monto de la evasión fiscal de $\$ 130,500,000,000.00$ ciento treinta mil quinientos millones de pesos en un ochenta por ciento.

Se tendrá que realizar una revisión detallada de los contribuyentes que emiten comprobantes fiscales por operaciones inexistentes que son autorizadas utilizando la página de internet del Servicio de Administración Tributaria por medio de la cual realizaron transacciones ilegales el gobierno federal, estatal y municipal por la cuantía de: $\$ 1,000,000,000,000.00$ un billón de pesos, de la cual el setenta por ciento es simulada y se utiliza para desviar recursos financieros $y$ quebrantar al país y a las finanzas públicas de cual la Secretaría de Hacienda y Crédito Público tiene pleno conocimiento.

Se presentó un amparo por parte de la empresa Rex Irrigación Zacatecas, S.A. de C.V., en contra de la inconstitucionalidad del artículo 25 fracción VI inciso a) de la Ley de Ingresos de la Federación para el 2019, publicado el día 28 de diciembre del 2018 en el diario oficial de la federación, por ir en contra de los apartados $1^{\circ}, 5^{\circ}, 14,16$ y 31 fracción IV de la Constitución Política de los Estados Unidos de México, así como del proemio 23 del Código Fiscal de la Federación y de los artículos $5^{\circ}$ fracción $\mathrm{V}$ inciso a) y $6^{\circ}$ de la Ley del Impuesto al Valor Agregado, así como de los apartados 2185, 2186 y 2194 del Código Civil Federal sobre el primer acto de aplicación que realizó mi representada en fecha día 07 de junio de 2017, con el cual se pretende eliminar de forma total ese proemio. 


\section{Tipo de Investigación}

La investigación que se aplicó para llevar a cabo esta indagación tiene dos enfoques la descriptiva y la aplicada, ya que está basada en lo siguiente información:

a) En un análisis minucioso y detallado de la doctrina respectiva del tema.

b) En la identificación y definición del problema a través de una pregunta.

c) En la formulación de una hipótesis efectuada a través de una pregunta en el problema.

d) En la deducción de sus consecuencias y definición de las variables.

e) En la edificación de un proyecto aplicado que representa a todos los elementos y sus conclusiones que fueron planteadas en la hipótesis.

\section{Métodos Teóricos}

En México se ha incrementado de manera exponencial los trámites que presentan los contribuyentes por concepto de aplicaciones de saldos a favor que luego se trasforman en compensación universales, éstas se aplican para el pago de los impuestos que resultan a cargo, y se materializan a través de la presentación de las declaraciones que pueden ser de manera mensual, semestral o anual según el régimen en que tributen.
El aumento en la evasión fiscal ha sido tan incalculable en materia del impuesto sobre la renta durante los últimos años, con respecto al monto que efectivamente pudieran recaudar las arcas del estado aplicando todo el peso de la ley, sin embargo, con el intercambio que se realiza de facturas por operaciones inexistentes entre distintos causantes, la baja participación en la recaudación por parte de los contribuyentes, el innumerable mundo de operaciones que se realizan con efectivo por parte de los ciudadanos de las cuales la autoridad fiscalizadora no tiene forma de auditarlas, ni revisarlas porque no dejan evidencia al momento que se realizan, esto aunado al hecho que la recaudación fiscal se ha convertido en un problema financiero $y$ económico muy serio para la elaboración de los presupuestos del gasto público nacional para nuestros diputados, y sumado a que el gobierno federal se ha visto muy corruptivo por tanto desvío de recursos a través de operaciones inexistentes durante los ejercicios del dos mil cinco al dos mil diecisiete, y que han llegado a representar hasta un veinte por ciento del total del ingreso programado del proyecto financiero que tiene que ser aprobado por el Congreso de la Unión con negociaciones turbias y poco transparentes por parte de nuestros legisladores, el monto de lo defraudado representa en promedio el tres por ciento con respecto al PIB nacional, de acuerdo con el estudio realizado por la Universidad de las Américas en el estado de Puebla (San Martín, Ángeles, Juárez \& Martín, 2017), el cual se representa de la siguiente manera:

En el año 2005 la tasa de evasión representó $49.4 \%$.

En el año 2006 la tasa de evasión representó $44.7 \%$.

En el año 2007 la tasa de evasión representó $39.3 \%$.

En el año 2008 la tasa de evasión representó $41.7 \%$.

En el año 2009 la tasa de evasión representó $47.5 \%$.

En el año 2010 la tasa de evasión representó $44.8 \%$. 
En el año 2011 la tasa de evasión representó $39.8 \%$.

En el año 2012 la tasa de evasión representó $40.2 \%$.

En el año 2013 la tasa de evasión representó $38.0 \%$.

En el año 2014 la tasa de evasión representó $38.0 \%$.

En el año 2015 la tasa de evasión representó $25.8 \%$.

En el año 2016 la tasa de evasión representó $19.2 \%$.

En el año 2017 la tasa de evasión representó $20.0 \%$.

Como puede observase la sumatoria de los porcentajes promedios de evasión fiscal del dos mil cinco al dos mil diecisiete representan un monto cuatrocientos ochenta y ocho punto cuarenta por ciento (San Martín , Ángeles, Juárez \& Martín, 2017) , y que en términos monetarios significa la cuantía aproximada de: $\$ 7,792,445,600,000.00 \quad$ siete mil billones setecientos noventa y dos mil cuatrocientos cuarenta y cinco millones seiscientos mil pesos, que si se dividiera entres los trece ejercicios fiscales representaría la cantidad de: $\$ 599,418,892,307.00$ de manera aproximada, resultados que son inaceptables, por lo que sólo los siete billones representa más que el presupuesto anual del ejercicio del dos mil nueve, cabe señalar al respecto, que entre los años dos mil diez y dos mil dieciocho la facturación ha crecido en un treinta y uno punto ocho por ciento de manera anual, pasando de setecientos sesenta punto treinta millones de facturas a novecientos veintiocho millones, pues está en línea con el crecimiento inaudito de los ingresos tributarios y los delitos.

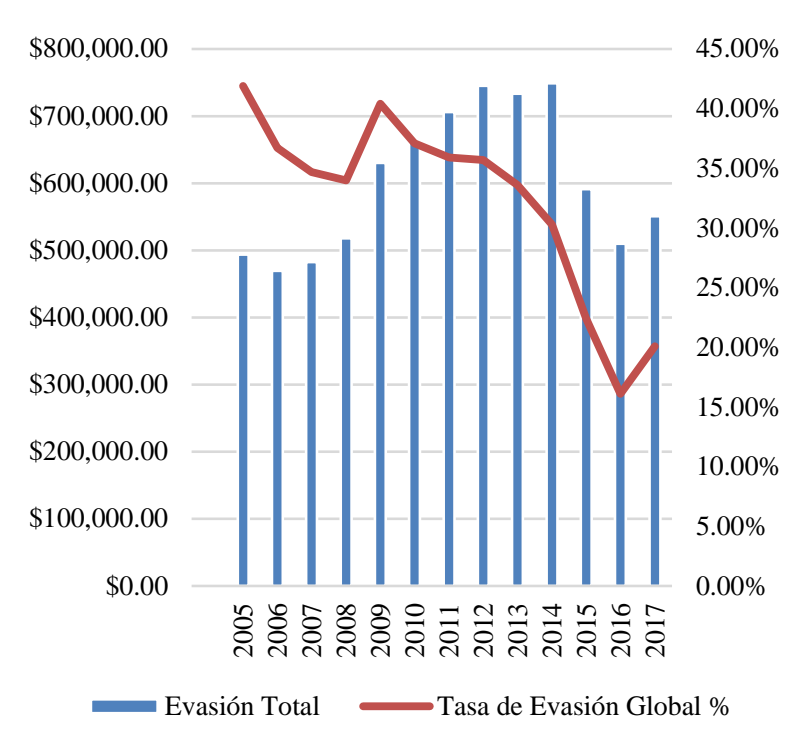

Gráfico 1 Evasión Fiscal (En miles de millones de pesos) Fuente:

http://omawww.sat.gob.mx/administracion_sat/estudios_ evasion_fiscal/Documents/Evasion_global2017.pdf

\section{Resultados}

El resultado final de la investigación que se proporciona mediante este documento utilizando una investigación indagatoria a través del examen de literaturas y fuentes diversas en la red, y de acuerdo con la hipótesis que fue planteada, así como de la recopilación de datos e informes nos permiten concluir con lo siguiente:

a) La compensación universal es una forma legal establecida en los artículos 23 primer párrafo del Código Fiscal de la Federación, $6^{\circ}$ de la Ley del Impuesto al Valor Agregado y 2185, 2186 y 2194 del Código Civil Federal, y por eso mismo tiene su propio valor probatorio, sin necesidad de irse ante los tribunales para su aplicación.

b) La compensación universal nace desde el momento mismo de la creación del hombre y desde el nacimiento de la agricultura cuando el ser humano empieza cultivar y a sembrar la tierra para sobre existir y generar productos para el comercio los cuales eran intercambiados a través del trueque, lo cual es imposible de erradicar por la naturaleza del comercio y lo que representa económicamente y financieramente a la sociedad. 
c) Que el uso indebido de compensaciones universales ha generado la compra de facturas por operaciones inexistentes y provocado un incremento desmedido de evasión fiscal por el importe $\$ 260,500,000,000.00$ doscientos sesenta mil quinientos millones y que representa aproximadamente el tres por ciento del producto interno bruto de la nación.

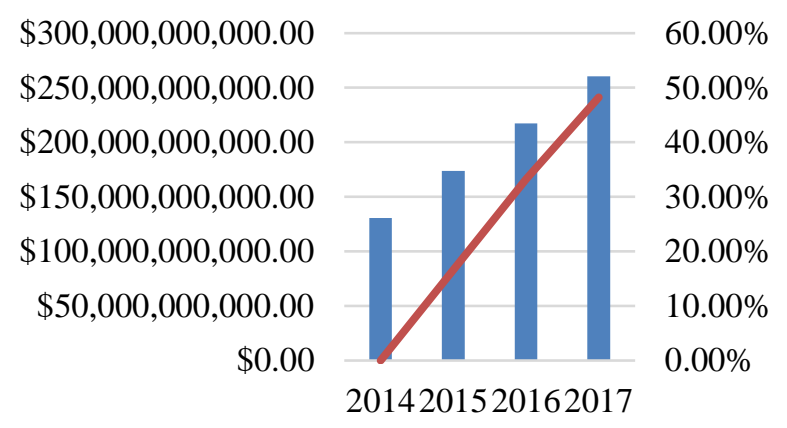

TOTAL (EN PESOS)

INCREMENTO (EN PORCENTAJE)

Gráfico 2 Incremento de Compensaciones Universales presentadas ante el Servicio de Administración Tributaria (SAT)

Fuente:https://www.eleconomista.com.mx/economia/Sen adores-confian-en-que-la-compensacion-universal-seretome-20190217-0066.html d) Que efectivamente sí se puede disminuir el porcentaje del setenta y seis de compra de facturas por operaciones inexistentes y que representa a la cantidad de $\$ 134,000,000,000.00$ ciento treinta y cuatro mil millones de pesos a través de la aplicación estricta de las normas penales y su debido proceso, con modificaciones adecuadas a las leyes secundarias, con una revisión física y material de las instalaciones, de sus procesos productivos $\mathrm{y}$ de sus empleados, utilizando la autoridad fiscalizadora la más avanzada tecnología satelital para descubrir la ubicación de las empresas que emiten comprobantes falsos por acciones aparentes, sin dañar las operaciones de terceros, y sobre todo que no se le restrinja el beneficio de la compensación universal en materia fiscal a la compañía Rex Irrigación Zacatecas, S.A. de C.V

e) Que se puede disminuir el porcentaje de corrupción hasta en un 70 por ciento y en un 90 por ciento la impunidad a través de la fiscalización estricta y con apego a derecho de los órganos de control siempre y cuando éstos estén integrados por miembros de la propia sociedad.

f) Se debe castigar a los funcionarios y empleados que realizan el setenta y seis por ciento de las conductas ilícitas, y que se han incrementado de manera indiscriminada por el uso indebido de las facturas apócrifas o simuladas, y en ese sentido, ha crecido de manera irracional en un treinta y uno punto ocho por ciento la carga administrativa para la autoridad fiscalizadora quedando corta la labor de sus revisiones.

g) Se debe solicitar el reintegro absoluto por parte del Servicio de Administración Tributaria del daño cometido al fisco federal, y penalizar las acciones dolosas y severas a los contribuyentes que evaden impuestos, de manera que la compensación universal vuelva a ser un medio limpio y confiable de extinguir una obligación fiscal por parte de los causantes. 


\section{Anexos}

Nota: este trabajo está referenciado con el expediente del recurso de amparo federal número 618/2019, el cual presentado en el Juzgado del Tercer Distrito con sede en Zacatecas, Zac., a nombre del actor Rex Irrigación Zacatecas, S.A.de C.V. y se encuentra pendiente de resolución.

\section{Agradecimientos}

A la Universidad Tecnológica del Norte de Aguascalientes: Por darme la oportunidad de integrarme a su cuerpo de estudiosos en el estado de Aguascalientes, y por otorgarme las herramientas para poder participar en tan importante revista de investigación y desarrollo al lado de la Dra. Marcela Rocha López y del Maestro Jorge Silva Robles quienes forman parte integral de este cuerpo colegiado de investigadores, es un privilegio y un honor compartir conocimientos y desarrollarlos para beneficio íntegro de los alumnos que pertenecen a la Dirección de Contaduría y Administración de esa institución tan prestigiada a nivel nacional.

\section{Conclusiones}

Con la presente investigación podemos concluir que la compensación es un medio natural por excelencia del derecho civil que extingue a las obligaciones, y que tiene lugar cuando dos personas reúnen la calidad de deudores y acreedores recíprocamente y por su propio derecho, a efecto, de extinguir las dos sus deudas; al respecto señalo que en la actualidad es extraño que el Servicio de Administración Tributaria y el gobierno federal utilizarán como pretexto el incremento en la defraudación fiscal a través de la emisión de comprobantes digitales apócrifos, cuando es la misma administración pública la que de manera exponencial ha incrementado de manera letal la autorización de la emisión de comprobantes fiscales digitales que sustentan las deducciones $\mathrm{y}$ por consecuencia a las compensaciones universales.
Los sustentos que señala la Secretaría de Hacienda y Crédito Público a través del Servicio de Administración Tributaria resultan absurdos e incomprensibles, ya que es muy desacertado señalar que se incrementó el monto de compensaciones en una cantidad aproximada de $\$ 130,500,000,000.00$ ciento treinta mil quinientos millones de pesos en tan sólo tres años al Congreso de la Unión, sin embargo, el importe total aproximado de los últimos trece años evasión representa un monto de $\$ 7,792,445,600,000.00$ siete mil billones setecientos noventa y dos mil cuatrocientos cuarenta y cinco millones seiscientos mil pesos, con lo que no se puede tapar el sol con un dedo, es decir, el gobierno federal pretende eliminar de manera perversa un derecho legítimo y tutelado en los apartados 23 del Código Fiscal de la Federación, $6^{\circ}$ de la Ley del Impuesto al Valor Agregado y 2185, 2186 y 2194 del Código Civil Federal por una situación embarazosa, señalando como base el incremento del importe de extinción de obligaciones fiscales se incrementó en más de un del cuarenta y ocho punto veinte cuatro por ciento, violentando los derechos humanos, las garantías individuales y los derechos fundamentales de los contribuyentes al privarlos de sus derechos legítimos como gobernados.

Es importante señalar al respecto, que siete de cada diez facturas que se emiten dentro de la nación son por operaciones inexistentes que se aprueban por el fisco mexicano, y sobre todo, van a parar a las arcas del gobierno federal, estatal o municipal y que por más candados que estén colocando dentro de la ley, los contribuyentes que más evaden están laborando para el estado mexicano y la cuantía se equipara a $\$ 1,000,000,000,000.00$ un billón de pesos, y lo más triste es, que no puede restringirle el gobierno mexicano el derecho a la compensación a los causantes cumplidos y honestos, en pocas palabras, el hijo está matando al padre y le está arrebatando el dinero de los contribuyentes para desviarlo y prácticamente embolsárselo de manera maligna quedando impune ante tales hechos. 
Es por eso que la empresa Rex Irrigación Zacatecas, S.A. de C.V., ante tanta descomposición del fisco federal en materia tributaria, ha decido buscar el amparo y la protección de la justicia federal a través del trámite 618/2019 presentado en el Juzgado del Tercer Distrito con sede en Zacatecas, Zac., con el objeto de que se rompa ese paradigma de restringir los derechos naturales de los contribuyentes por la incompetencia en la recaudación de las autoridades federales, estatales y municipales de las cuales los gobernados están muy cansados de sus ilegales acciones, es decir, el aparato burocrático que dirige al país ya calló en el hartazgo de la mayoría de los mexicanos por el primer evasor de las contribuciones en México.

Por lo pronto no se ha logrado la suspensión provisional del acto reclamo en el amparo presentado por la empresa Rex Irrigación Zacatecas, S.A. de C.V., sin embargo, lo más seguro es que se otorgará la protección y justicia de ley, y se dejará de aplicar el artículo 25 fracción VI inciso a) de la Ley de Ingresos de la Federación para el 2019, publicado el día 28 de diciembre del 2018 en diario oficial de la federación por resultar inconstitucional por parte de la compañía.

\section{Referencias}

ABCNOTICIAS. (2019). La Procuraduría de la Defensa del Contribuyente informó a la Cámara de Diputados que a un billón de pesos podría ascender el desvio de recursos públicos con facturas falsas. 2019, de ABCNOTICIAS Sitio web: https://www.abcnoticias.mx/utilizanfacturas-falsas-en-gobiernos/115942

Bedrossian, G. (2017). El instituto de la compensación económica en el Código Civil y Comercial. 2019, de abogadosdemendoza.com Sitio web: https://www.abogadosdemendoza.org/post/elinstituto-de-la-compensacion-economica-en-elcodigo-civil-y-comercial

Boletin Fiscal: EY. (2019). Compensación universal. 2019, de Boletin Fiscal: EY Sitio web:

http://www.eyboletin.com.mx/comentarios/BF Comentario060728_1.pdf
Bonilla, M. (2013). Historia del comercio. Agosto, 2019, de LinkedIn Sitio web: https://es.slideshare.net/MarcelaBonilla/historia -del-comercio-26996173

El Financiero. (2019). Cuánto crecerá la economía de México en 2019? Aquí los pronósticos más optimistas y pesimistas. Agosto 2019, de Economía Sitio web: https://www.elfinanciero.com.mx/economia/cua nto-crecera-la-economia-de-mexico-en-2019aqui-los-pronosticos-mas-optimistas-ypesimistas

Fernández, M. (2017). Derechos de obligaciones. 2019, de digibug Sitio web: http://digibug.ugr.es/bitstream/handle/10481/48 179/FernandezBaquero_DerechosdeObligacion es.pdf? sequence $=1 \&$ is Allowed $=\mathrm{y}$

García, C. (2014). Compensación. 2019, de Enciclopedia Jurídica Online Sitio web: https://mexico.leyderecho.org/compensacion/

Gómez. (2014). Apuntes de Derecho Romano. 2019, de Universidad Libre Sitio web: http://www.unilibre.edu.co/cartagena/pdf/invest igacion/libros/derecho/DERECHO\%20ROMA NO.pdf

Homs, R. (2019). La Compensación Universal. 2019, de El Universal Sitio web: https://www.eluniversal.com.mx/columna/ricar do-homs/la-compensacion-universal

Marino, A. (2019). Babilonios. Agosto, 2019, de Historiando Sitio web: https://www.historiando.org/origen-del-trueque/

Marino, A. (2019). Origen del trueque. Agosto, 2019, de Historiando Sitio web: https://www.historiando.org/origen-del-trueque/

Montoya, O. (2018). Compensación. 2019, de Diccionario Jurídico Sitio web: $\mathrm{http}: / / \mathrm{www}$.diccionariojuridico.mx/definicion/c ompensacion/

Paulino J. (2010). EXTINCION DE LAS OBLIGACIONES. Agosto, 2019, de Derecho Romano Sitio web: http://derechoromanoii.blogspot.com/2010/03/e xtincion-de-las-obligaciones.html

Reyez, L. (2012). Derecho Romano II. Estado de México: Tercer Milenio S.C 
Saldívar, B. (2019). Senadores confian en que la compensación universal se retome. Agosto, 2019, de El Economista Sitio web: https://www.eleconomista.com.mx/economia/S enadores-confian-en-que-la-compensacionuniversal-se-retome-20190217-0066.html

Salomón, I. (2018). Así afectará la eliminación de la compensación universal a las empresas. 2019, de Expansion Sitio web: https://expansion.mx/empresas/2018/12/17/asiafectara-la-eliminacion-de-la-compensacionuniversal-a-las-empresas

San Martín, J., Ángeles, H., Juárez, C. \& Martín, J. (2017). Evasión Global 2017. 2019, de UNIVERSIDAD DE LAS AMÉRICAS PUEBLA Sitio web: http://omawww.sat.gob.mx/administracion_sat/ estudios_evasion_fiscal/Documents/Evasion_gl obal2017.pdf

Secretaría de Hacienda y Crédito Público. (2017). Informe Semanal del Vocero. Agosto, 2019, de Comunicado Sitio web: https://www.gob.mx/cms/uploads/attachment/fi le/269709/051117_Informe_del_Vocero_No._4 4.pdf 